\title{
Retinal findings in Malawian patients with AIDS
}

\author{
Susan Lewallen, Jonny Kumwenda, Dermot Maher, Anthony D Harries
}

\begin{abstract}
The purpose of this study was to determine the prevalence of retinal disease in a group of patients with AIDS in Malawi. Indirect ophthalmoscopy was performed on 99 patients with AIDS who were admitted consecutively to a medical ward at a central hospital. Necrotising retinitis was present in one eye of one patient examined. Non-infectious retinopathy was present in $13 \%$. Retinitis is less common in AIDS patients from Africa compared with those from developed countries; it is believed that most patients die before acquiring it. Non-infectious retinopathy may also be less common.
\end{abstract}

(BrF Ophthalmol 1994; 78: 757-759)

Retinal pathology is a well recognised manifestation of HIV infection and AIDS in developed countries. Estimates of the proportion of patients with AIDS who have retinal pathology vary. Non-infectious retinopathy (isolated haemorrhages and cotton wool spots) occurs in $50-70 \%$ of patients at some time in the course of disease. ${ }^{12}$ Cytomegalovirus (CMV), herpes simplex virus, and varicella zoster virus may all cause severe necrotising retinitis..$^{34} \mathrm{CMV}$ is the most common of these; it occurs in approximately $15-30 \%$ of AIDS patients and is the most common cause of blindness in AIDS patients in developed countries. ${ }^{25}$

Most reports on retinal findings in AIDS have been based on studies of patients from developed countries. However, the World Health Organisation currently estimates that over two thirds of the world's AIDS cases occur in sub-Saharan Africa. ${ }^{6}$ In a small prospective study from Rwanda no patients with AIDS or AIDS related complex developed CMV retinitis. ${ }^{7}$ To our knowledge, there are no other published reports on retinal findings in a general population of AIDS patients in Africa. HIV infection and AIDS differ in several important ways in Africa compared with developed countries. In subSaharan Africa the infection is spread almost exclusively by heterosexual contact and virtually all sexually active persons are considered to be at risk. The burden of disease in Africa is associated with patients in the early stages of HIV infection who present with, and frequently die from, such diseases as pneumococcal pneumonia, invasive salmonella, and tuberculosis. ${ }^{8-10}$ Although antibodies to CMV are widespread in the general population of African adults, " clinical CMV infection in HIV infected and AIDS patients in Africa is reported to be uncommon. ${ }^{89}$

Malawi has one of the highest rates of HIV infection in Africa and AIDS is a major cause of death among the adult population. HIV seroprevalence among urban women attending prenatal clinics at the Queen Elizabeth Central Hospital
(QECH) in Blantyre is $31 \%$ (personal communication, Johns Hopkins University/Ministry of Health Research Project) and HIV seroprevalence in surrounding rural areas is estimated to be about half of this. Around 3000 to 5000 patients are examined every month in the eye outpatient department at QECH but only one patient with active retinitis has presented there during the past 3 years. There are several possible explanations for this. Retinitis may be rare in Africa, patients with retinitis may be too ill to present for ocular examination, or patients with AIDS in Africa may die before developing retinitis. In order to estimate the prevalence of retinal pathology in AIDS we performed ocular examinations on 99 consecutive AIDS patients admitted to the medical wards at QECH.

\section{Patients and methods}

QECH is the central referral hospital for the southern region of Malawi (population 5 million) and the only site in which an ophthalmologist is available in the region. During October and November 1993, patients admitted to the nonpaying medical wards (general medicine and tuberculosis) at QECH who met established criteria for diagnosis of AIDS were enrolled consecutively. All patients were examined by a medical specialist physician to establish the diagnosis of AIDS and eye examinations were all conducted within a few days of admission by one ophthalmologist. A diagnosis of AIDS required a positive enzyme linked immunosorbent assay (ELISA) test for HIV and the presence of at least two major signs and one minor sign in the World Health Organisation clinical case definition of AIDS for use in Africa. ${ }^{12}$

As many of these patients were too ill to be moved, eye examinations were performed at the bedside. Visual acuity was checked with an $\mathrm{E}$ chart by a trained eye nurse after which pupils were dilated with $1 \%$ tropicamide and $2.5 \%$ phenylephrine. The ophthalmologist examined the external eye and anterior segment with a torch, then examined the retina by indirect ophthalmoscopy. Findings were recorded on a standard form.

\section{Results}

Ninety nine patients were enrolled and examined. There were 63 men (median age 32 years, range $19-60$ years) and 36 women (median age 30 years, range $14-55$ years). Table 1 shows the clinical features of AIDS in the patients. In addition to fulfilling the WHO clinical case definition of AIDS for use in Africa, 58 patients had pulmonary tuberculosis and 10 had extrapulmonary tuberculosis.

Seventy three patients had normal eye examinations. The findings in the other 26 are shown 
Table 1 Clinical features of AIDS

\begin{tabular}{ll}
\hline Feature & $\begin{array}{l}\text { Number of patients } \\
(n=99)\end{array}$ \\
\hline Weight loss $>10 \%$ & 97 \\
Diarrhoea $>1$ month & 43 \\
Fever $>1$ month & 86 \\
Cough > 1 month & 82 \\
General lymphadenopathy & 16 \\
Previous herpes zoster & 1 \\
Oropharyngeal candidiasis & 36 \\
Recurrent herpes simplex & 1 \\
Cryptococcal meningitis & 1 \\
Generalised Kaposi's sarcoma & 1 \\
\hline
\end{tabular}

Table 2 Ocular findings in AIDS patients

\begin{tabular}{llll}
\hline & \multicolumn{2}{l}{ Number of patients } & \\
\cline { 2 - 3 } Ocular finding & $\begin{array}{l}\text { With TB } \\
(n=68)\end{array}$ & $\begin{array}{l}\text { Without } T B \\
(n=31)\end{array}$ & $\begin{array}{l}\text { Total } \\
(n=99)\end{array}$ \\
\hline Normal examination & 53 & 20 & 73 \\
Cotton wool spots & 8 & 5 & 13 \\
Haemorrhages & 1 & 2 & 3 \\
Papilloedema & 2 & 1 & 3 \\
Vitreous debris & 1 & 2 & 3 \\
Healed iritis & 2 & 0 & 2 \\
Peripheral vascular sheathing & 1 & 0 & 1 \\
Retinal oedema & 0 & 1 & 1 \\
Retinitis & 1 & 0 & 1 \\
Choroiditis & 1 & 0 & 1 \\
\hline
\end{tabular}

$\star$ Total is $>99$ because some patients had more than one finding.

in Table 2. Visual acuity was $6 / 12$ or better in both eyes of 92 patients (with the exception of one eye blind from childhood trauma). Four other patients had vision at least $6 / 18$ in both eyes but were too ill to cooperate fully with the examination; these patients had no retinal pathology which would be expected to decrease vision. An additional two patients were too obtunded to check visual acuity; one of these had a normal fundus and the other had bilateral mild generalised retinal oedema with a cherry red spot and very narrow vessels. This latter patient, with slim disease and generalised oedema, died several hours after the examination and the eye findings may have been premortem rather than AIDS related. Only one patient (with retinitis, described below) had decreased visual acuity (in one eye only) which we thought was AIDS related.

Fifteen $(22 \%)$ patients with tuberculosis had abnormal eye examinations compared with 11 (33\%) abnormal eye examinations in the patients without tuberculosis (difference not statistically significant, $\mathrm{p}>0 \cdot 1$ ). The patient with choroiditis had suspected, but not bacteriologically proved, tuberculous meningitis; the choroiditis was bilateral and consisted of diffuse thickening of the choroid with sparing of the maculae (visual acuity $6 / 6$ both eyes). The two patients with previous iritis both had pulmonary tuberculosis. Both had posterior synechiae, but no anterior chamber inflammation or keratic precipitates on slit-lamp examination. Both gave a history of sore, red eyes which resolved spontaneously a few months before initiation of tuberculosis treatment. The retinitis was present in a patient with pulmonary tuberculosis and consisted of yellow, necrotic retina and haemorrhage in the midperiphery, mild vitreous haze, and a tractional posterior retinal detachment (visual acuity $6 / 60$ ); the fellow eye had a normal fundus (visual acuity 6/6).

\section{Discussion}

Tuberculosis is the most common opportunistic infection in patients in sub-Saharan Africa who die from AIDS, ${ }^{13}$ thus the large number of patients in this study with tuberculosis is expected. Ocular lesions clearly associated with tuberculosis, however, were not found.

Our data support the idea that retinitis is less common in AIDS patients in sub-Saharan Africa than those in developed countries. Furthermore, only $13 \%$ of our patients manifested noninfectious retinopathy. The patients were not examined serially; had they been, it is likely that a larger number would have manifested this transient retinopathy. None the less, we may compare this series with one from the USA in which 28 of 67 AIDS patients had non-infectious retinopathy on initial examination. ${ }^{14}$ Although there could be differences in baseline characteristics between these groups of AIDS patients which make comparisons invalid, the findings suggest that non-infectious retinopathy may be less common among African AIDS patients than those in developed countries. The presence of non-infectious retinopathy as well as CMV retinitis is associated with decreased CD4 counts. ${ }^{14}$ It may be that AIDS patients in subSaharan Africa die sooner, with higher CD4 counts, than AIDS patients in developed countries but, to our knowledge, there are no studies that confirm this. We did not have the facility to measure CD4 counts. Among HIV positive tuberculosis patients in Abidjan, Cote d'Ivoire, and Kinshasa, Zaire, CD4 counts were greater than 200 in $61 \%$ and $67 \%$ of patients respectively. ${ }^{15} 16$ The mean CD4 count of AIDS patients enrolled in a survival analysis in the Gambia was $280 .{ }^{17}$

This hospital based series represents patients with advanced disease which would be a likely group in which to find retinitis in African patients. We think that most African patients with AIDS die before they develop blinding retinitis. In spite of the increasing numbers of AIDS patients in many African countries, retinitis is not creating a significant new burden for ophthalmic services.

1 *Holland GN, Pepose JA, Pettit TH, Gottlieb MS, Yee RD, Foos RY. Acquired immune deficiency syndrome: ocular manifestations. Ophthalmology 1983; 90: 859-72.

2 Pepose JS, Holland GN, Nestor MS, Cochran AJ, Foos RY. Acquired immune deficiency syndrome: pathogenic Acquired immune deficiency syndrome: pathogenic
mechanisms of ocular disease. Ophthalmology 1983; 92: mechanism.

$3 \mathrm{Ai} \mathrm{E}$, Wong KL. Ophthalmic manifestations of AIDS. Ophthalmol Clin N Am 1988; 1: 53-61.

4 Margolis TP, Lowder CY, Holland GN, Spaide RF, Logan AG, Weissman SS, et al. Varicella-zoster virus retinitis in patients with the acquired immunodeficiency syndrome. Am f Ophthalmol 1991; 112: 119-31.

5 Peters BS, Beck EJ, Anderson S, Coleman D, Coker R, Main $\mathrm{J}$, et al. Cytomegalovirus infection in AIDS. Patterns of disease, response to therapy and trends in survival. F Infect 1991; 23: 129-37.

6 World Health Organisation. The HIV/AIDS Pandemic: 1993 Overview. WHO/GPA/CNP/EVA/93.1. Geneva.

7 Kestelyn P, Van de Perre P, Rouvroy D, Lepage P, Bogaerts J Nzaramba $D$, et al. A prospective study of the ophthalmo-
ald logic findings in the acquired immune deficiency syndrome in Africa. Am $\mathcal{F}$ Ophthalmol 1985; 100: 230-8.

8 Colebunders RL, Latif AS. Natural history and clinical presentation of HIV-1 infection in adults. AIDS 1991; 5 (suppl 1): 103-12.

9 Lucas SB, Odida $M$, Wabinga $H$. The pathology of severe morbidity and mortality caused by HIV infection in Africa. AIDS 1991; 5(suppl 1): 143-8.

10 Gilks CF. The clinical challenge of the HIV epidemic in the developing world. Lancet 1993; 342: 1037-9. 
11 Benenson AS, ed. Control of communicable diseases in man. 15th ed. Washington DC: American Public Health Association, 1990: 115-6.

12 World Health Organisation. Provisional clinical case definition for AIDS. Week Epidemiol Rec 1986; 61: 72-3

13 DeCock KM, Soro B, Coulibaly IM, Lucas SB. Tuberculosis and HIV infection in sub-Saharan Africa. FAMA 1992;268: 1581-7.

14 Freeman WR, Chen A, Henderly DE, Levine AM, Luttrull JK, Urrea PT, et al. Prevalence and significance of acquired immunodeficiency syndrome-related retinal microvasculopathy. Am f Ophthalmol 1989; 107: 229-35. 15 De Cock K. The new tuberculosis. Africa Health 1994; 16 : 8-10

16 Mukadi Y, Perriëns JH, St Louis ME, Brown C, Prignot J, Willame J-C, et al. Spectrum of immunodeficiency in HIVl-infected patients with pulmonary tuberculosis in Zaire. Lancet 1993; 342: 143-6.

17 Whittle H, Egboga A, Todd J, Corrah T, Wilkins A, Demba $\mathrm{E}$, et al. Clinical and laboratory predictors of survival in Gambian patients with symptomatic HIV-1 or HIV-2 Gambian patients with sympt
infection. AIDS 1992; 6: 685-9. 